Introduction

\title{
Constructing grassroots innovations for sustainability
}

One of the cleavages within sustainable development is division between grassroots environmental action, often deemed good on participation terms, and green innovation, usually centred on technologies in firms and deemed good for ecological modernisation. This special section is dedicated to an obvious and missing connection: grassroots innovation for sustainability.

Grassroots innovations typically involve networks of activists and organisations generating novel bottom-up solutions for sustainable development; solutions that respond to the local situation and the interests and values of the communities involved (Seyfang and Smith, 2007). What they share is commitment on the part of those involved towards openness and inclusion in the processes of innovation and the outputs of innovation.

Research is still needed that considers whether and how grassroots innovators network with one another; the extent to which movements for grassroots innovation approaches exist and how they operate; whether and how innovations diffuse through processes of replication, scaling-up, and translation into institutions; and whether or not these developments constitute alternative pathways for sustainability. The empirical contributions in this special section consider the dilemmas of going to scale, the challenges of moving from innovation to institutionalisation, and the risks of capture and instrumentality when grassroots innovations encounter more powerful political economies of conventional innovation systems (see also Smith et al., 2013). A recurring theme is diversity in innovation for sustainability; which might be served best by resisting pressures to mainstream, yet simultaneously generates accusations of marginality.

In highlighting these themes and introducing the special section, we use a particular example, the Brighton Earthship, and which all contributing authors visited as part of a research workshop on grassroots innovation held at Sussex University in May 2012 and that led to the papers here.

\section{Objects for engagement}

An Earthship is a low energy, off-grid, earth-sheltered dwelling whose principal structural and thermal materials are local mud and old car tyres. Like similar eco-house structures, the Earthship has developed through many years of experimentation. In this case design and development centred in a group led by Mike Reynolds, living and working in the desert of Taos, New Mexico (Reynolds, 1990). Inspired by Mike during an earlier visit to the UK in 2000, a Brighton group decided to build an Earthship. With financial support coming via from landfill tax grants, the group self-built their Earthship (http://www.lowcarbon.co.uk/earthship-brighton).
It serves as a community centre for Stanmer Organics food project. According to the group, several thousand people have visited the Earthship, including Secretary of State David Milliband, MP, and reporters from over 100 mainstream media outlets. In this respect, the Earthship has joined other grassroots innovation objects engaging publics in discussions about sustainability.

\subsection{Context-sensitivities and scaling-up grassroots innovation}

Earthship designs were fine tuned over many years of experimentation and learning-by-doing in the Taos desert amongst networks of collaborating self-builders. Principles of passive solar heating, rainwater harvesting, on-site power supply and wastewater treatment, and patterns and practices of working together in building and dwelling in their constructions. Manuals, plans, and Mike's crew were available to diffuse the design internationally, as they did in Brighton.

However, the particularities of the site in Brighton, including its climate, planning restrictions, and underdeveloped markets for component materials and technologies required adaptations and considerable re-innovation. Implementing the designs challenged group dynamics and required effective local knowledge to be built up. This provided some with skills and know-how relevant for subsequent grassroots projects locally. Diffusing grassroots innovations is not straightforward. Not only does it require innovative re-contextualisation, but the processes involved also involve the intangible diffusion of, for example, the new skills embodied in those involved into other areas of activity.

\subsection{Grassroots innovations that try to stretch and transform rather than fit and conform}

The Earthship design is radical not only in its use of materials and off-grid form. The associated scripts for constructing and living are quite different. Earthships are designed to be open to collaborative, self-build approaches quite unlike the conventional labour markets used by volume house-builders. They involve patterns of inhabitation and use different to those customary in conventional buildings.

These processes are transformative for those involved. They also presuppose a 'fit' with yet-to-be-transformed socio-technical systems that are either emerging or still absent in everyday practices. For example, markets for affordable micro-generation technologies, cultures of inhabitation typical of green-minded occupants, or the development of efficient processes for assembling the tyre-and-mud structure. Convincing building regulators that the novel materials and form were safe, and negotiating the 
necessary permits, was hard work, slowed the process, increased costs, and demonstrated the poor fit between the Earthship and conventional building institutions.

\subsection{Project-based approaches to structural challenges}

Some of the impediments to the transformative potential of the Earthship design derive from deeper-rooted, structural relations of economic and political power. With persistent persuasion and lobbying, institutions like building regulations can be revised to permit some novel grassroots construction techniques. Deeperseated reforms that open resources to grassroots experimentation will be much more difficult to bring about.

Structures of land ownership, for example, can exclude grassroots groups and be an impediment not just in eco-building, but also for community energy projects, food projects, and other sustainability initiatives. Some grassroots innovators are forced to operate on the margins, such as the deserts around Taos, where structural constraints are felt less keenly, and experimentation is possible with fewer resources. In the case of the Brighton Earthship, the group accessed publicly owned land dedicated to community food projects; the building was promoted as providing appropriately green services for those projects. But the structural challenges could just as easily relate to the difficulty existing knowledge institutions have in capturing the lessons from grassroots innovation and turning them into norms for building and dwelling more widely.

\subsection{Grassroots innovation and recognising the value of diverse knowledge production}

In living with challenges like those above, grassroots innovators generate a plurality of forms of knowledge. Some of that knowledge is instrumental, technical even, and addresses questions about how to do sustainability. Other forms of knowledge derives from questions of what kinds of sustainability, for whom, and are more akin to ethnographic research uncovering meanings, identifications and how the innovative activity weaves in and out of peoples' lives. A third form of knowledge production found across many grassroots innovation movements is more critical in character. In doing something out of the ordinary, or out of necessities unmet by market and state, grassroots responses reveal the limitations for some sustainabilities of current political, economic and social structures.

So, quite apart from the material objects produced by grassroots innovation, an incredibly valuable diversity of knowledge and know how for innovation for sustainability is generated, even if policies and markets only adapt and appropriate a part of it, or more frequently overlook it entirely. Challenges manifesting in Brighton did generate considerable knowledge of ethnographic, instrumental and critical character. And yet, only a limited portion has been captured for wider engagement and use. Instrumental knowledge about Earthship performance has been codified and disseminated through activities such as monitoring the energy properties of the building and reporting its construction techniques (Hewitt and Telfer, 2007).

Knowledge that is more ethnographic in character, regarding for example the circumstances and aims of the groups involved, their dynamics, the meanings and significance of the Earthship in relation not just to conventional construction but also to social practices of dwelling, and whether and how the Earthship has inspired and informed similar approaches to sustainability in other groups, has not been captured. Some of the critical knowledge generated, about the challenges of voluntary work on this kind of project, accessing land, and negotiating the consent of various institutions, has similarly struggled to gain attention beyond academic study.

\section{Contributions to the special section}

Two papers in this special section validate the plural knowledge and capacity-building benefits arising through grassroots innovation. Kirwan and colleagues analyse grassroots networks in the UK that received Big Lottery funding for community access to affordable local food (Kirwan et al., in this issue). Their in-depth, qualitative research finds the funded initiatives met this aim. But the findings also reveal significance resting not so much in the quantities of food produced and consumed (which is limited), so much as in the diverse knowledge and associated material, personal and cultural capacities built through those activities. This begs questions about the means and metrics of evaluation. Growing food can be a vehicle for learning in a more ethnographic vein about how, for example, to engage disadvantaged groups in fulfilling activities for all involved, as well as critical knowledge about where and how participants can work food and other systems to one's advantage.

Taking a different approach, White and Stirling consider communal growers in East Sussex in the UK (White and Stirling, in this issue). They explain various group strategies for 'sustainability' in the face of dependency upon agents beyond communal growers. Some strategies seek to influence the wider context, others adapt to those contexts. Initiatives have to inter-relate with wider systems beyond food, including health and education, and which re-frames communal growing in ways that proliferate innovative ideas and combinations.

Studying different community ownership initiatives for supplying electricity from daylight using rooftop solar photovoltaics, Hess analyses how the associated power relations disadvantage and frustrate grassroots framings of urban energy (Hess, in this issue). The innovation and diffusion of solar electricity involves different socio-technical designs whose various forms of organisation, ownership, and economic model compete. Grassroots configurations are contrasted with corporate configurations. Interestingly, the firms promoting a corporate roll out of PV come from outside incumbent electricity business. The former include ICT firms whose access to finance and political decision-making is decisive not only for out-competing grassroots approaches, but also for providing a countervailing power to incumbent electricity business. Interestingly, this is no straightforward three-way competition. Rather, important interdependencies are revealed in the ways grassroots experiments provide appropriable components (e.g. organisational models) for commercial socio-technical configurations, and how such appropriations motivate grassroots reactions for more inclusive community responses.

Ornetzeder and Rohracher identify a similar dynamic in the grassroots origins of commercial innovations in solar water heating in Austria, wind turbines in Denmark, and car sharing in Switzerland (Ornetzeder and Rohracher, in this issue). Analysing the local structural contexts that grassroots actors draw upon to support initiatives, learning processes, and institution-building, they consider how these also shape relationships with market actors. Whilst propitious for scaling-up, for some of the pioneers the directions taken in institutionalising these innovations have been disappointing.

Reactions and redirections amongst grassroots activists keeps open the search for more transformative innovations. In recent years this has been particularly evident in the field of communitybased sustainable energy. The paper by Hargreaves and colleagues interrogates how this community (re-)turn has been helped in the UK by the activities of intermediary organisations working between communities (Hargreaves et al., in this issue). Trying to assemble and transmit lessons, experience, and support between diverse initiatives that operate across quite different social, economic, and political settings proves demanding. Some forms 
of intermediation work better than others. Limited infrastructures and resources for these tasks inhibit more involved forms of support, exacerbated by energy institutions developed around large-scale and centralised energy practices.

All papers note how difficult is sustaining community-led initiatives. The social economy can be an important source of resources as much, if not more, than the capitalist economy. Complementary currencies are an interesting enabling grassroots innovation. These currencies are themselves a form of grassroots innovation. Seyfang and Longhurst explore how processes for social learning, networking, and developing expectations explain the development and status of complementary currencies internationally (Seyfang and Longhurst, in press). As with other grassroots innovations, but pronounced here, value-plurality complicates and challenges more narrow measures of competitive success typically sought in commercial settings.

\section{Theories of grassroots innovation}

Looking across the papers, it becomes clear that the characteristics of the 'spaces' that grassroots innovations occupy are important for their development. Some papers, though not all, adopt a 'niche' conceptualization (Kemp et al., 1998). Contributors find such thinking helpful, but only up to a point. The more managerial thinking in the niche analysis literature is found, perhaps unsurprisingly, to be less appropriate amidst the messier pluralities and voluntary associations of grassroots innovation.

The importance of identities, community dynamics and power relations in grassroots innovation is underplayed by strategic niche management approaches. Hess suggests field theory from sociology can address some of the power relational issues. Other approaches could be used. A relatively obvious body of work here are studies of social movements, and how they create and occupy spaces for grassroots transformation. Alternatively, personal and group engagements in grassroots innovations generate developments, practices and objects open to theoretical inquiry in social practice theory, material culture, and other fields. Diverse grassroots knowledge production and its politics can be interrogated with concepts from the sociology of knowledge. The variety of new lines of theoretical inquiry is wide.

\section{Looking and linking beyond the special section}

There are other absences in this collection. One obvious area is the growing body of work in grassroots innovation in the Global South. Here, local necessities combine with (post-)development discourses to frame grassroots innovation activity in altogether different ways. The cultures, institutions, economies, politics and possibilities for grassroots innovation vary enormously. And yet, a look into the activities of the Honey Bee Network and People's Science Movement in India, for example, or movements for social technologies in Latin America, or grassroots innovation in South East Asia or Africa, suggest similar challenges to those above but playing out in very different circumstances (Gupta et al., 2003; Abrol, 2011; Dagnino, 2009; Miranda et al., 2011; Smith et al., 2013).

Empirically, the contributions cover housing, energy, food, exchange, and mobility. All are important, but so too is grassroots innovation in water and sanitation, health and disease, information and communication, citizen's science, recycling and materials, natural resource management, biodiversity, public spaces, education, the arts, and many other domains of social life. What many contributions do indicate, however, is how classifications into neat domains do not always work for grassroots activities. Food initiatives can engage as much, if not more, with public health, education, or youth training, as they do with the consumption and production of food. Grassroots innovations are no respecters of boundaries. This can cause difficulties when engaging with institutions and their more bounded logics.

The linkages across sectors and across spaces are there to be made. The emergence in recent years of a global movement for commons-based, peer-production, involving international networks of community fabrication workshops, such as hackerspaces, is a good example of the new directions and possibilities for grassroots innovation made by such linking. Open experimentation with digital design and machine tools across these spaces using social media opens up a variety of prospects for grassroots digital fabrication (Smith and Hielscher, 2013).

Those studying and supporting grassroots innovation need to remain alert to developments like these, to better understand the linkages and the challenges faced by grassroots initiatives, and engage grassroots innovators in explorations of whether and how they might navigate a course for wider recognition and support as part of a wider democratic politics of innovation in society.

\section{References}

Abrol, D., 2011. Innovation Lessons from the design of innovation systems for rural industrial clusters in India Lessons from the Design of Innovation Systems for Rural Industrial Clusters in India. Asian Journal of Technology Innovation 12 (2) $37-41$.

Dagnino, R., 2009. Tecnologia social: ferramenta para construir outra sociadade.

Gupta, A.K., et al., 2003. Mobilizing grassroots' technological innovations and traditional knowledge, values and institutions: articulating social and ethical capital. Futures 35 (9) 975-987.

Hargreaves, T., Hielscher, S., Seyfang, G., Smith, A., 2013. Grassroots innovations in community energy: the role of intermediaries in niche development. Global Environmental Change (in this issue).

Hess, D., 2013. Industrial fields and countervailing power: the transformation of distributed solar energy in the United States. Global Environmental Change (in this issue).

Hewitt, M., Telfer, K., 2007. Earthships in Europe. BRE Press, Watford.

Kemp, R., Schot, J., Hoogma, R., 1998. Regime shifts to sustainability through processes of niche formation: the approach of strategic niche management. Technology Analysis \& Strategic Management 10 (2) 175-198.

Kirwan, J., Ilbery, B., Maye, D., Carey, J., 2013. Grassroots social innovations and food localisation: an investigation of the Local Food programme in England. Global Environmental Change (in this issue).

Miranda, I., Lopez, M., Soares, M.C.C., 2011. Social technology network: paths for sustainability. Innovation and Development 1 (1) 151-152.

Ornetzeder, M., Rohracher, H., 2013. Of solar collectors, wind power, and car sharing: comparing and understanding successful cases of grassroots innovations. Global Environmental Change (in this issue).

Reynolds, M., 1990. Earthship: How to Build Your Own. Solar Survival Architecture, Taos, New Mexico.

Seyfang, G., Smith, A., 2007. Grassroots innovations for sustainable development: towards a new research and policy agenda. Environmental Politics 16(4) 584-603.

Seyfang, G., Longhurst, N., 2013. Desperately seeking niches: grassroots innovations and niche development in the community currency field. Global Environmental Change (in this issue)

Smith, A., Fressoli, M., Thomas, H., 2013. Grassroots innovation movements: contrbutions and challenges. Journal of Cleaner Production (in press).

Smith, A., Hielscher, S., 2013. Grassroots digital fabrication: reconfiguring, relocating and recalibrating productio and consumption? In: Sustainable Consumption Research and Action Initiative Conference. Clark University, Worcester, Mass.

White, B., Stirling, A., 2013. Sustaining trajectories towards sustainability: dynamics and diversity in uk communal growing activities. Global Environmental Change (in this issue).

Adrian Smith* SPRU (Science and Technology Policy Research), University of Sussex, UK

Gill Seyfang $3 S$ (Science, Society and Sustainability), University of East Anglia, UK

*Corresponding author. Tel.: +44 1273877065 E-mail address: A.G.Smith@sussex.ac.uk (A. Smith)

6 July 2013 